\title{
THE INDWELLING CATHETER IN PARAPLEGICS
}

\author{
With Particular Reference to Urethral Diverticula
}

By Professor R. Ascoli

Milan

IN my view the key points are these:

I. The catheter is obviously an invaluable instrument in the treatment of urine retention secondary to paraplegia and in urinary dysfunctions of paraplegics generally. risks.

2. But if it is not used appropriately and thoughtfully, it carries considerable

3. The risks involved are chiefly these: if applied for a long time, especially from the beginning of the accident, and particularly with high-level lesions, that is cervical or dorsal, the indwelling catheter can constitute a major danger owing to the fact that the bladder can become a 'small neurogenic bladder', which cannot be re-educated at a later stage, because the bladder has become small, inelastic and sclerotic and the patient may become prone to attacks of paroxysmal hypertension at the slightest attempt to distend it.

4. I remember quite a number of cases in which the attacks of paroxysmal hypertension were terrible to see, and they came on unfailingly whenever any attempt was made to distend the bladder, by irrigation, or simply when the indwelling catheter was removed. This was followed by bouts of headache, general malaise, hyperhidrosis and rise in blood pressure. Of course, this does not occur in all cases, but the risk is always there and has to be borne in mind.

To recap, one must be on one's guard against using the indwelling catheter for long periods, especially in high-level lesions, that is dorsal and, even more, cervical lesions.

5. I am of the opinion-and I do not think I am alone in this-that long-term use of the indwelling catheter is prejudicial to the bladder's contractile and expulsive activity. It is a general rule in patho-physiology and traumatology that organs should be kept working, otherwise they get lazy and risk atrophy, which jeopardizes the chances of subsequent reablement.

So I am not saying anything new when I say that right from a very early period it is a good thing for the bladder to be subjected to alternate filling and rapid emptying with a rhythm similar to that of normal micturition. This can be attained by any one of the several methods proposed, such as intermittent catheterisation, occluded indwelling catheter, that is opened at regular intervals, or tidal drainage.

At any rate, the majority of authors are agreed that it is preferable to keep the bladder working, and that an absolute collapse of the bladder, especially for long periods of time, is harmful. Nevertheless the use of an indwelling catheter is not particularly dangerous for short periods.

6. The indwelling catheter is a serious risk for the urethra, since it is obviously a more or less traumatising foreign body that may-since the environment is always a slightly septic one-be a cause of septic trouble in the wall, urethritis, periurethritis, abscesses and periurethral infiltrations, which in the end can pave the way 
for fistulae. One of the main complications of the consequences of such urethral damage are urethral diverticula and urethral fistulae.

It is well known that the acquired urethral diverticulum, which is especially frequent among paraplegics, is only a secondary stage of periurethritis. It is well known that periurethritis may be followed by either the formation of a diverticulum, or-if the septic process is particularly severe and suitable therapy is not appliedby the formation of a urethral fistula.

I shall not quote all the data of the medical literature existing on this subject, I would, however, mention that of 28 diverticula observed in paraplegics, Bate and Bunts noted a frequency of 13.6 per cent. but only 5.5 per cent. of these cases occurred in their department, a fact which indicates that the frequency is clearly lower in departments specialising in the treatment of paraplegics.

In I95 I Comarr and Bors found 6I cases of penoscrotal diverticulum out of 122 paraplegics on whom cystourethrography had been performed (frequency of 50 per cent.). Of 6I9 paraplegics 43 cases of fistula (6 per cent.) were observed. In 35 per cent. of these cases spontaneous recovery occurred. With conservative surgical treatment 7.5 per cent. of cases showed favourable results; after more radical surgery 75 per cent. of the 40 cases treated showed favourable results. Three cases were not treated.

In the cases I observed during the period 1957-59, including also cases previously treated by other centres, I observed three diverticula in a total of $2 \mathrm{I}$ cystourethrographies. In two cases slight irregularities of the urethral contour were observed following operations for fistula. The total number of paraplegics observed in this period was 96. In the subsequent period covering the years I960 to 1966 we observed only six urethral diverticula on a total of 4I cystourethrographies. It must, however, be noted that these patients were hardly ever hospitalised in our department from the onset of the disease. In the great majority they unfortunately were admitted to our department several days, weeks or months after the accident. It is, therefore, very probable that the onset of the periurethritic process which was the cause of the diverticulum, dates back to the period when the patient was hospitalised in other non-specialised hospitals, often not equipped in any way for the treatment of paraplegics.

It emerges from all these data that in 62 patients radiologically studied during the period I957-66, a diverticulosis occurred in I4 per cent. The incidence in our two periods of observation was about the same. Among the diverticula observed two were of such vast dimensions to be classified as giant diverticula (figs. I and 2). Both cases occurred in the first period, 1957-59. There was also a case of double diverticula. Regarding the onset, they developed as early as one month (in one case) or as late as several years after the trauma.

Urethral fistulae call for a separate comment. During the period I957-66 we observed Io cases of fistula. Of these seven were admitted with a fistula already formed, or with an abscess which needed immediate incision, resulting in the formation of a fistula. In three cases, on the other hand, periurethritis resulting in fistula formation developed in our department. In a total of $27 \mathrm{I}$ paraplegics observed in the same period, the incidence was therefore 3.6 per cent., but it was only I I per cent. in patients admitted to our department from the onset of the illness. Regarding the prevention of diverticula and of urethral fistulae, they can best be prevented by the use of very thin catheters, preferably rubber and size I2 F. 


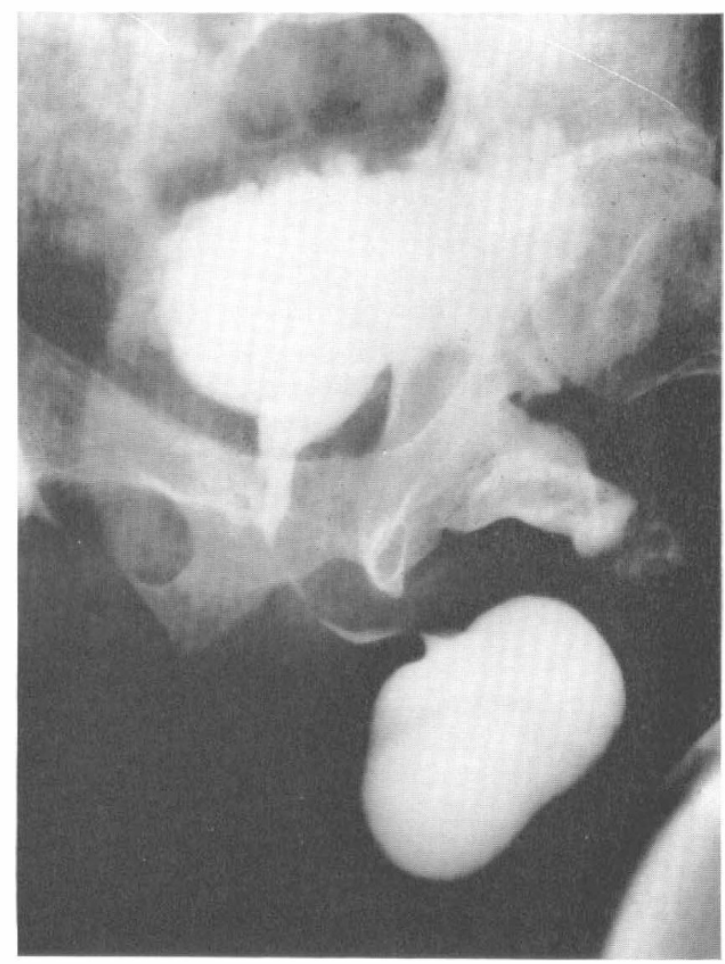

FIG. I

Cysto-urethrography in a case of giant diverticulum in paraplegic.

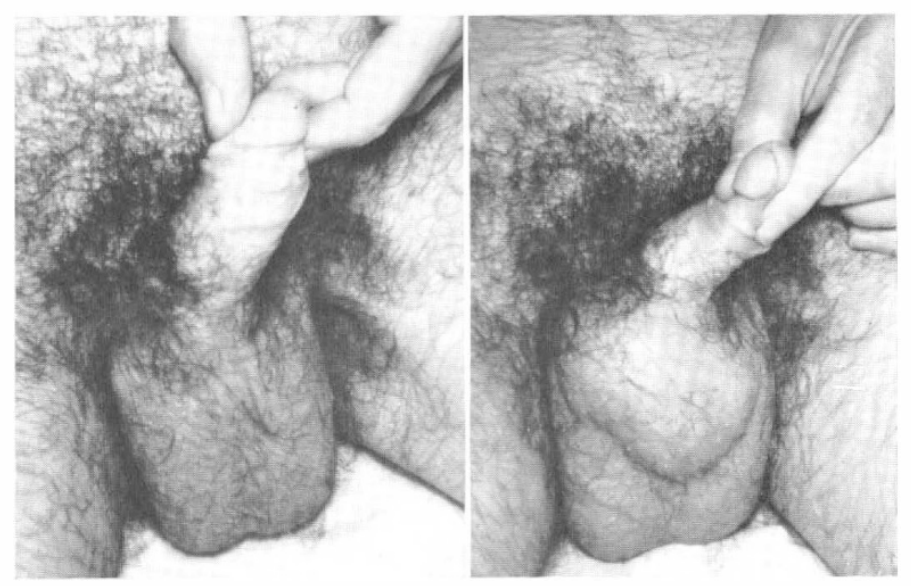

FIG. 2

The same case as in Fig. I. Left, before filling of urethra; right, after filling of urethra and diverticulum. 
7. Steps must be taken to minimise these risks, and the method practised in our department of the Milan Traumatology Center is as follows:

For over Io years now I have been using only very fine catheters of soft rubber. Thiemann type with four or six holes.) Rubber catheters are less hard and therefore less traumatising than plastic ones. Furthermore, the Foley balloon catheter is used only in exceptional cases, because experience in a large number of cases has convinced me that the presence of this round foreign body in the bladder is often traumatising to the wall of the bladder, and constitutes an irritant to be avoided, especially in hypertonic-hyperkinetic bladders. Moreover, it prevents perfect drainage, since good drainage demands drainage of urine from the lowest part of the bladder. The presence of the balloon, of the Foley catheter, makes this impossible since the tip of the catheter, where the urine should enter, lies always fairly high up.

8. It goes without saying that catheters must be carefully watched and changed frequently, and that catherisation should be carried out very gently and by an expert hand. The nature of the lubricant is very important too. I, normally, use sterilised vaseline oil, kept in a container which does not allow the liquid to flow along the external non-sterile part of the container neck.

The catheter must be changed fairly often, usually every 5 to 6 days, or whenever it is seen to be not working properly, because mineral deposits have formed inside or because it has been displaced.

9. I am appalled when paraplegic patients are referred to us from nonspecialist centres wearing catheters of wide, sometimes enormous, size, such as 22 or even $24 \mathrm{~F}$, semirigid and sometimes very old and hard-I may say antiquewhich have lost any elasticity and softness. This sort of thing should be avoided at all cost.

Io. With the system as described above urethral damage from indwelling catheters in paraplegics in our department is exceedingly rare. Although the incidence of diverticula is I4 per cent., most of them already existed at the time of admission to our department. The incidence of fistulas is 3.6 per cent., but only I'I per cent. of these occurred in our department.

I I. Apart from loss of contractility, and permanent shrinkage of the bladder due to fibrosis, the main damage to the bladder develops from septic processes. The first of these is cystitis, acute or chronic, which can hardly be avoided in paraplegics. However, provided the catheter works properly and provided patients are properly treated with antiseptics, the harm is not serious and it is of no clinical importance.

There can be more serious complications, such as perivesical abscesses due to perforation of the bladder. These must, of course, be treated surgically.

I2. In general, my practice is to use catheters as sparingly as possible in paraplegics. Obviously, in the first two-three months one cannot help using them; we are using either intermittent catheterisation or tidal drainage or the 'intermittent occluded' method, but not the method of indwelling catheter which is the worst of all systems. It is advisable to get rid of the indwelling catheter as soon as possible. Generally speaking, the average paraplegic can do without a catheter as early as the third month after the accident if suitable treatment has been used, and from the fourth or fifth month in nearly all cases. 
13. The use of an indwelling catheter for an indefinite time puts the paraplegic at a severe disadvantage also psychologically, for he has one more ground for feeling inferior and dependent upon other people. We have to do all we can to make the paraplegic feeling normal and self-reliant, and, if possible, carrying on working. Using the system described, nearly all the paraplegics discharged from my department no longer need catheters after 3 to 5 months, with the sole exception of cases with reflux. Generally a certain degree of residual urine remains, and in about half the cases the urine is slightly cloudy, but there are no clinical troubles worth mentioning. 